\title{
Development of oral capsules from E nterica herbal decoction-a traditional remedy for typhoid fever in Ghana
}

\author{
Doris Kumadoh $^{1,3 *}$, Joseph Adotey ${ }^{2,3}$, Kwabena Ofori-Kwakye ${ }^{3}$, Samuel Lugrie Kipo ${ }^{3}$, Thomford Prah ${ }^{1}$, Sowah \\ Patterson $^{1}$ \\ ${ }^{1}$ Centre for Scientific Research into Plant Medicine (CSRPM), P.O. Box 73, Mampong-Akwapim, Ghana. ${ }^{2}$ Department of Pharmaceutical Science, School \\ of Applied Sciences, Central University College, Miotso, Ghana; ${ }^{3}$ Department of Pharmaceutics, Faculty of Pharmacy and Pharmaceutical Sciences, \\ Kwame Nkrumah University of Science and Technology, Kumasi, Ghana.
}

\section{ARTICLE INFO}

Article history:

Received on: 04/12/2014

Revised on: 17/01/2015

Accepted on: $12 / 02 / 2015$

Available online: $27 / 04 / 2015$

\section{Key words:}

Herbal medicine, Herbal

extracts, Absorbents, Herbal

capsules, Maize starch, Light

magnesium carbonate

\begin{abstract}
The study aimed to develop oral capsules from Enterica herbal decoction used in Ghana for the treatment of typhoid fever and produced by the Centre for Scientific Research into Plant Medicine (CSRPM). The amount of dry extract per dose $(30 \mathrm{ml})$ of Enterica and the wavelength of maximum absorption $(\lambda \max )$ of aqueous solutions of Enterica extract were determined. Light magnesium carbonate (LMC) and maize starch (MS) were employed as absorbents at various concentrations in the preparation of granules of the extract. The \% loss in weight, size distribution and flow properties of the granules were evaluated. Enterica oral capsules were formulated using LMC at $22 \mathrm{mg} /$ dose of extract and the dissolution properties of the granules and capsules were determined by UV-VIS spectrophotometry. The dry Enterica extract/dose was $190.1 \pm 0.12 \mathrm{mg}$ and $\lambda$ max was $356 \mathrm{~nm}$. The loss of granules was 2.07-7.31\%w/w for LMC and 2.73-7.81\%w/w for MS. LMC granules (22 mg/dose) prepared for encapsulation exhibited good flow properties. The granules for encapsulation exhibited optimal release of extract $(86.08 \pm 1.64 \%$ at $45 \mathrm{~min})$ in aqueous medium. The formulated capsules passed the British Pharmacopoeia uniformity of weight, disintegration and dissolution tests. Enterica oral capsules can be used as a substitute for Enterica decoction for the treatment of typhoid fever.
\end{abstract}

\section{INTRODUCTION}

Herbal product design refers to the process of developing, standardizing, processing, and validating an herbal product for the market. Herbal medicine products may be consumed for purposes such as improvement of health, improvement of physical appearance, weight loss, or enhancement of well-being. Herbal products may come in formulations such as decoctions, infusions, tinctures, syrups, elixirs, linctuses, lozenges, pills, tablets, capsules (Barrett, 2004; Database of National Products Association, 2006-2011). The quality of herbal medicine is believed to be directly related to its active principles (Capasso et al., 2004). The principal objective of dosage form design is to achieve a predictable therapeutic response to a drug included in a formulation which is capable of large scale manufacture with reproducible product quality. To ensure

* Corresponding Author

Email: selasie100@yahoo.com product quality, numerous features are required: chemical and physical stability, suitable preservation against microbial contamination if appropriate, uniformity of dose of drug and acceptability to users. Excipients provide varied and specialized pharmaceutical functions (Aulton, 2002). Pharmaceutical absorbents which may be considered as excipients are usually solids, with a large surface area which can attract dissolved or finely dispersed substances from another medium by physical or chemical (chemisorption) means. Examples include microcrystalline cellulose, maize starch, magnesium carbonate, kaolin, bentonite and fumed silica (McCarty, 2004). Pharmaceutical absorbents have recently been successfully employed in the formulation of granules and oral capsules from herbal decoctions (Johnson et al., 2010; Bayor et al., 2011; Johnson et al., 2011; Kumadoh et al., 2014). Enterica is an herbal decoction formulated and produced by the Centre of Scientific Research into Plant Medicine (CSRPM), Mampong-Akwapim, Ghana. Enterica decoction which is produced under the name 'Mist Enterica' is extensively used in the treatment of typhoid fever at 
CRSPM's herbal clinic in Mampong-Akwapim, Ghana. It has been reported that over 40, 000 bottles of Mist Enterica produced by the Production Department of CRSPM were dispensed at the Centre's clinic in 2004 alone (CSRPM Biennial Report, 2003-2004). Enterica herbal decoction consists of a combination of plant materials obtained from twelve plants, namely: Spondias mombin, Persea americana, Psidium guajava, Trema orientalis, Cnestis ferruguinea, Momordica charantia, Vernonia amygdalina, Latana carnara, Paullinia pinnata, Citrus aurantifolia, Morinda lucida and Bidens pilosa. The antimicrobial activities of these plants are well documented in the literature (McGaw et al., 2000; Chowdhury and Islam, 2004; Jagessar et al., 2008; Olayemi et al., 2013; Gomez-Flores et al., 2008; Biswas et al., 2013; Shittu et al., 2014; Fakoya et al., 2014). The purpose of the current study is to develop oral capsules from Enterica decoction by employing absorbents in the preparation of granules of the dry extracts. The preparation of granules from Enterica decoction will permit the preparation of the herbal product into solid dosage forms such as tablets and capsules to increase the choice of patients who may not prefer the decoction. The preparation of granules and capsules will enhance the standardization of this popular Ghanaian herbal remedy; improve patient compliance leading to improved treatment outcomes.

\section{MATERIALS AND METHODS}

\section{Materials}

Maize starch (Tradewinds Chemists, Kumasi, Ghana); microcrystalline cellulose, kaolin, bentonite (Drug Pharm Trading, The Netherlands) and light magnesium carbonate (Fisons Scientific, U.K.) were used as absorbents. Lactose and talc were obtained from the Chemical Store, Pharmaceutics Department, KNUST, Kumasi, Ghana. All other chemicals and reagents used in this study were of analytical grade.

\section{Preparation of Enterica decoction}

Plant materials obtained from twelve tropical plants, namely: Spondias mombin, Persea americana, Psidium guajava, Trema orientalis, Cnestis ferruguinea, Momordica charantia, Vernonia amygdalina, Latana carnara, Paullinia pinnata, Citrus aurantifolia, Morinda lucida and Bidens pilosa were collected, dried and processed into powder by staff of CSRPM according to a classified formula. A decoction of Enterica was prepared by boiling $50 \mathrm{~g}$ of the processed plant materials in $1.25 \mathrm{~L}$ of water for $30 \mathrm{~min}$. The mixture was allowed to stand for $24 \mathrm{~h}$ to macerate and then strained with calico after decanting. The residue was washed with hot water to make up the product volume.

\section{Preparation of Enterica granules}

Samples of Enterica decoction were evaporated to a thin concentrated extract in a hot air oven at $60{ }^{\circ} \mathrm{C}$ for $48 \mathrm{~h}$. Drying containers with base diameters of $0.16 \mathrm{~m}$ and $0.30 \mathrm{~m}$ containing various volumes of the decoction (0.5-2 L) were used for evaporating the decoctions and the characteristics of the resulting extracts recorded. The weight of extract per dose $(30 \mathrm{ml})$ of
Enterica decoction was also determined. The absorbents (maize starch, kaolin, light magnesium carbonate, bentonite and microcrystalline cellulose) were mixed individually with thin extracts of Enterica (moisture content $<5 \%$ w/w) at a concentration of 22, 44, 66, 88 and $110 \mathrm{mg}$ absorbent per dose (30 $\mathrm{ml}$ ) of decoction. Further drying was carried out to obtain a completely dry extract-absorbent mix. The dry products formed were scrapped and were each screened through $850 \mu \mathrm{m}$ sieve to obtain Enterica granules containing different amounts of absorbents. The ease of scrapping and processing was noted and the percentage loss in weight of dry product calculated.

\section{Evaluation of size distribution and flow properties of granules}

The Enterica granules prepared were screened and sorted into coarse and fine granules using a $425 \mu \mathrm{m}$ sieve. The flow properties of the granules formulated for encapsulation were further characterized using indirect methods, namely: bulk density measurements (Hausner ratio and Carr's index) and angle of repose (fixed height cone method) (Staniforth and Aulton, 2007).

\section{Formulation of Enterica capsules}

Five hundred (500) Enterica capsules each with a nominal weight of $350 \mathrm{mg}$ were prepared from granules consisting of Enterica extract (54. $30 \% \mathrm{w} / \mathrm{w})$, light magnesium carbonate $(6.30 \% \mathrm{w} / \mathrm{w}$ equivalent to $22 \mathrm{mg}$ per dose $)$, lactose $(38.40 \% \mathrm{w} / \mathrm{w})$ and talc $(1 \% \mathrm{w} / \mathrm{w})$. Enterica extract was thoroughly mixed with light magnesium carbonate to form a uniform paste which was dried in a hot air oven at $60{ }^{\circ} \mathrm{C}$ and screened through $850 \mu \mathrm{m}$ sieve, after which lactose was added. The dry extract-absorbent granules formed were lubricated with talc and filled into size 1 hard gelatin capsule shells using a semi-automated capsule filling machine (Model TMP Mini T-50).

\section{Assessment of quality of capsules}

The Enterica capsules prepared were evaluated for uniformity of weight (BP 2009, Appendix XII C1). Twenty Enterica capsules were randomly selected and weighed individually with an analytical balance. Each capsule was carefully opened and the content removed totally. The difference between the weight of the intact capsule and the empty shell was calculated for each capsule. The mean weight of the twenty capsules was calculated and the percentage deviations determined. Disintegration test on Enterica capsules was undertaken (BP 2009, Appendix XII A1) using an Erweka disintegration apparatus (ZT $3 / 1$, GmbH Heusenstamm, Germany) at $37 \pm 0.5{ }^{\circ} \mathrm{C}$ with distilled water as disintegrating medium. A disc was placed on each capsule to prevent it from floating. The time taken for all six capsules to disintegrate leaving only remnants of gelatin shell on the mesh was recorded. The procedure was repeated twice and the mean disintegration time recorded.

\section{Preparation of calibration plot}

Crude extract of Enterica was obtained by drying the decoction at $60{ }^{\circ} \mathrm{C}$ in a hot air oven to obtain extracts with 
moisture content of less than $5 \% \mathrm{w} / \mathrm{w}$. The maximum wavelength of absorption of the extract was obtained by scanning various concentrations (0.0001-0.1\% w/v) of aqueous solution of Enterica crude extract using a UV-Visible spectrophotometer (Cecil 7200). The absorbance values of aqueous solutions of crude extracts of Enterica $(0.00625-0.025 \% \mathrm{w} / \mathrm{v})$ were determined at $356 \mathrm{~nm}(\lambda$ max) for Enterica from which a calibration plot was obtained for subsequent estimation of extracts released from formulated granules and capsules in aqueous media.

\section{Dissolution of Enterica granules and capsules}

Dissolution tests of Enterica granules and capsules were carried out using an Erweka dissolution apparatus (DT 6, GmbH Heusenstamm, Germany). Capsules containing approximately $190.0 \mathrm{mg}$ Enterica extract and granules equivalent to $190.0 \mathrm{mg}$ Enterica extract were used. The dissolution medium was $900 \mathrm{ml}$ distilled water; paddle speed: $50 \mathrm{rpm}$; sampling time: 5, 10, 15, 30, 45 and $60 \mathrm{~min}$; and temperature: $37 \pm 0.5{ }^{\circ} \mathrm{C}$. Five millilitre samples of dissolution medium were withdrawn at the specified time intervals and replaced with $5 \mathrm{ml}$ of fresh distilled water. The withdrawn samples were immediately filtered through $0.45 \mu \mathrm{m}$ HA membrane filters and the absorbance measured with a UV spectrophotometer in a $1 \mathrm{~cm}$ cell at a wavelength of $356 \mathrm{~nm}$. The amount of Enterica extract in the samples was determined using a regression data obtained from the calibration plot of Enterica extract in aqueous medium. The percentage release of Enterica from each sample was calculated (mean \pm SD., $n=3$ ), and a dissolution profile plotted.

\section{Statistical analyses}

The dissolution data were subjected to one-way ANOVA followed by Bonferroni's multiple comparison tests using GraphPad Prism version 5.00 for Windows (GraphPad Software, San Diego California, USA, www.graphpad.com). Differences between samples were considered significant when $\mathrm{p}<0.5$.

\section{RESULTS AND DISCUSSION}

Enterica decoctions were successfully dried in a hot air oven and the mean weight of Enterica extract per dose of Enterica decoction was determined to be $190.1 \pm 0.12 \mathrm{mg}$. Table 1 presents the influence of diameter of container and quantity of decoction on the nature of Enterica extract after drying at $60{ }^{\circ} \mathrm{C}$ in a hot air oven. The quantity of decoction of Enterica per unit area of container which dried completely was $21.21 \mathrm{~L} / \mathrm{m}^{2}$. Table 2 presents the ease of scrapping and processing of the dry extracts into granules after drying. It was generally very easy to scrape and process the dry extracts into granules after evaporation to dryness when light magnesium carbonate and maize starch were used as absorbents, while kaolin, bentonite and microcryatalline cellulose were less easy to process. Light magnesium carbonate and maize starch were therefore selected for further work. In a recent study, absorbents ( $\geq 80 \mathrm{mg} / \mathrm{dose}$ ) were employed in the formulation of oral capsules from Asena decoction and the absorbents were shown to improve drying, decrease drying time and enhances the scrapping and further processing of the extracts into granules and oral capsules (Kumadoh 2011; Kumadoh et al., 2014). Thus, the ease of granule processing from dry extracts of herbal products should be a major factor for consideration when production is to be undertaken on a large scale.

Table 1: Effect of diameter of drying container and amount of decoction on nature of extract after drying Enterica decoction at $60{ }^{\circ} \mathrm{C}$.

\begin{tabular}{lllll}
\hline Container & $\begin{array}{c}\text { Diameter } \\
\text { of base of } \\
\text { container } \\
(\mathbf{m})\end{array}$ & $\begin{array}{c}\text { Area of base } \\
\left(\boldsymbol{\pi} \mathbf{r}^{\mathbf{2}}\right) \text { of } \\
\mathbf{c o n t a i n e r} \\
\left(\mathbf{m}^{\mathbf{2}}\right)\end{array}$ & $\begin{array}{c}\text { Quantity } \\
\text { of } \\
\text { decoction } \\
(\mathbf{L})\end{array}$ & $\begin{array}{c}\text { Nature of } \\
\text { extract after } \\
\mathbf{d r y i n g}\end{array}$ \\
\hline A & 0.16 & 0.0201 & 0.5 & Dried \\
B & 0.16 & 0.0201 & 1.0 & Dried \\
C & 0.16 & 0.0201 & 1.5 & Dried \\
D & 0.30 & 0.0707 & 0.5 & Dried \\
E & 0.30 & 0.0707 & 1.0 & Dried \\
F & 0.30 & 0.0707 & 1.5 & Dried \\
G & 0.30 & 0.0707 & 2.0 & Gummy \\
\hline
\end{tabular}

Table 2: Ease of scrapping and processing of dry Enterica extracts prepared with $110 \mathrm{mg}$ absorbent/dose of Enterica decoction.

\begin{tabular}{lll}
\hline Absorbent & Ease of scrapping & Ease of processing \\
\hline Maize starch & Very easy & Very easy \\
Light magnesium carbonate & Very easy & Very easy \\
Kaolin & Very difficult & Very difficult \\
Bentonite & Easy & Easy \\
Microcrystalline cellulose & Easy & Easy \\
\hline
\end{tabular}

The percentage loss in weight of formulated granules was established based on the formulation of granules of Enterica using absorbents for hundred doses of the product. Results from Table 3 indicate that the percentage loss in weight of Enterica granules produced with light magnesium carbonate and maize starch ranged from $2.07-7.31 \%$ and $2.73-7.81 \%$, respectively.

Table 3: Percentage loss in weight of Enterica granules produced using light magnesium carbonate and maize starch as absorbents.

\begin{tabular}{lllll}
\hline \multirow{2}{*}{ Absorbent } & $\begin{array}{l}\text { Weight of } \\
\text { absorbent } \\
\text { /dose (mg) }\end{array}$ & $\begin{array}{l}\text { Expected } \\
\text { weight of } \\
\text { granules } \\
\text { (g) }\end{array}$ & $\begin{array}{l}\text { Actual } \\
\text { weight of } \\
\text { granules } \\
(\mathbf{g})\end{array}$ & $\begin{array}{l}\text { Weight } \\
\text { loss }(\%)\end{array}$ \\
\hline \multirow{2}{*}{ Light magnesium } & 22 & 21.20 & 20.56 & 3.02 \\
carbonate & 44 & 23.40 & 21.69 & 7.31 \\
& 66 & 25.60 & 23.96 & 6.41 \\
& 88 & 27.80 & 26.40 & 5.04 \\
Maize starch & 110 & 30.00 & 29.38 & 2.07 \\
& 22 & 21.20 & 20.14 & 5.00 \\
& 44 & 23.40 & 22.03 & 5.85 \\
& 66 & 25.60 & 23.60 & 7.81 \\
& 88 & 27.80 & 26.44 & 4.89 \\
& 110 & 30.00 & 29.18 & 2.73 \\
\hline
\end{tabular}

The percentage loss in weight of granules was independent of the amount of absorbent used for granulation. Table 4 shows the size distribution of Enterica granules formulated using the two selected absorbents. Light magnesium carbonate granules had size distribution of 42.99-46.93\% coarse and 53.07-57.01\% fines, while maize starch granules had 54.02-62.63\% coarse particles and $37.37-45.98 \%$ fines. Thus, granules formulated using light magnesium carbonate possessed more fine granules than that formulated using maize starch. Particle size can affect the 
dissolution rate and absorption of pharmaceutical formulations. In general, the smaller the particle size, the faster is the dissolution (Podczeck and Jones, 2004).

Table. 4: The size distribution of Enterica granules formulated using light magnesium carbonate and maize starch as absorbents.

\begin{tabular}{llll}
\hline Absorbent & $\begin{array}{l}\text { Weight of } \\
\text { absorbent/do } \\
\text { se (mg) }\end{array}$ & $\begin{array}{l}\text { Coarse } \\
\text { granules } \\
(\%)\end{array}$ & $\begin{array}{l}\text { Fine } \\
\text { granules } \\
(\mathbf{\%})\end{array}$ \\
\hline \multirow{3}{*}{ Light magnesium carbonate } & 22 & 44.75 & 55.25 \\
& 44 & 46.93 & 53.07 \\
& 66 & 42.99 & 57.01 \\
& 88 & 43.56 & 56.44 \\
Maize starch & 110 & 45.13 & 54.87 \\
& 22 & 55.66 & 44.34 \\
& 44 & 54.02 & 45.98 \\
& 66 & 62.63 & 37.37 \\
& 88 & 56.54 & 43.46 \\
& 110 & 56.27 & 43.73 \\
\hline
\end{tabular}

Enterica granules for encapsulation were formulated using $22 \mathrm{mg}$ of light magnesium carbonate per dose of decoction. The granules generally exhibited good flow properties with a Hausner ratio of 1.24, Carr's index of $19.04 \%$ and angle of repose of $35^{\circ}$. Good flow properties of granules will enhance the uniform filling of capsules in capsule filling machines (Kumadoh et al., 2014), hence the uniformity of weight test of formulated capsules may indicate whether the granules used for encapsulation possessed good or poor flow properties. Granules produce particle-size uniformity, thus content uniformity (Kunii and Levenspiel, 1991). The UV spectrum of $0.02 \% \mathrm{w} / \mathrm{v}$ Enterica extract in distilled water showed a clear marker at maximum wavelength of absorption ( $\lambda$ max) of $356 \mathrm{~nm}$. A linear calibration plot with $\mathrm{R}^{2}$ of 0.9979 (Figure 1) was obtained showing a good relationship between the concentration of the marker and absorbance. This indicates that absorbance values of aqueous solutions of Enterica at $\lambda \max 356 \mathrm{~nm}$ can be used to quantify the active principles present in the herbal formulation which are responsible for its therapeutic efficacy. Figure 2 shows the dissolution data of granules formulated using five different absorbents. Granules formulated using light magnesium carbonate and maize starch had relatively higher release of extracts from Enterica granules $(>69 \%)$ than from granules formulated with kaolin, bentonite or microcrystalline cellulose $(<35 \%)$. Further work was therefore undertaken to determine the effect of change in quantity of maize starch and light magnesium carbonate on the dissolution characteristics of formulated granules of Enterica. Figure 3 shows the dissolution profiles of Enterica granules prepared using 22, 44, 66, 88, and $110 \mathrm{mg} /$ dose of light magnesium carbonate and maize starch. The amount of active ingredients released from Enterica extracts, granules and capsules were determined from regression data $(y=33.91 x+0.0052)$ obtained from the calibration plot of Enterica extract in aqueous medium at a wavelength of $356 \mathrm{~nm}$. The percentage release of formulations of granules for encapsulation and capsules should not be less than $75 \%$ at 45 min (Shittu et al., 2014). Optimum release of Enterica extract was obtained from granules formulated using $22 \mathrm{mg}$ light magnesium carbonate /dose of Enterica, achieving
$86.08 \pm 1.64 \%$ release in $45 \mathrm{~min}$. Release from $22 \mathrm{mg}$ light magnesium carbonate/dose granules was significantly higher $(\mathrm{p}<0.5)$ than that of maize starch at the same concentration. Drug release from granules containing 44, 66, 88 and $110 \mathrm{mg}$ light magnesium carbonate were not significantly different $(\mathrm{p}>0.5)$ from that of maize starch at the same concentration.

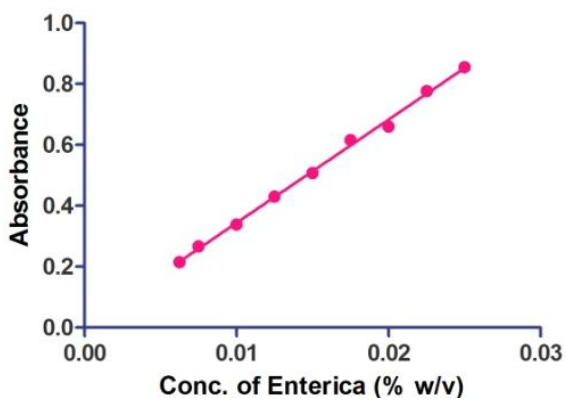

Fig. 1: Calibration plot for Enterica extract in aqueous medium.

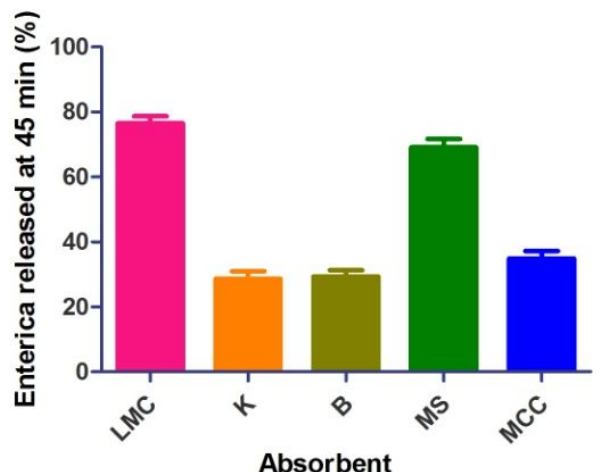

Fig. 2: Percentage release of Enterica from granules prepared using five different absorbents at $110 \mathrm{mg}$ absorbent per dose (mean $\pm \mathrm{SD}, n=3$ ). (LMClight magnesium carbonate, K - Kaolin, B - Bentonite, MS - Maize starch, MC- Microcrystalline cellulose)

Light magnesium carbonate granules at $44 \mathrm{mg} / \mathrm{dose}$ and $66 \mathrm{mg} /$ dose produced release rates of $77.69 \pm 2.17 \%$ and $81.22 \pm$ $1.74 \%$, respectively, showing their suitability for encapsulation. The remaining granule formulations, however, had release rates $<75 \%$ in 45 min, making them less suitable for encapsulation. An herbal medicinal extract prepared using absorbents may thus require a study of the release profile to assure adequate release in order to ensure optimum therapeutic action. Figure 4 shows the dissolution profile of Enterica oral capsules formulated using 22 $\mathrm{mg} / \mathrm{dose}$ of light magnesium carbonate as absorbent, compared to that of Enterica granules. The dissolution profiles of the two formulations were similar $(\mathrm{p}>0.5)$. The formulated Enterica capsules passed the BP dissolution test $(84.51 \pm 1.51 \%$ dissolved at $45 \mathrm{~min}$ ) as well as uniformity of weight test with only one capsule having percentage deviation of $-8.03 \%$ (acceptable range of deviation: $\pm 7.5 \%$ for a minimum of 18 capsules and $\pm 15 \%$ for a maximum of two capsules). The capsules also passed the BP disintegration test with mean disintegration time of $4.26 \pm 0.34$ min. Enterica granules and oral capsules produced with light magnesium carbonate at a concentration of $22 \mathrm{mg} / \mathrm{dose}$ are suitable alternative dosage forms for Enterica decoction. 

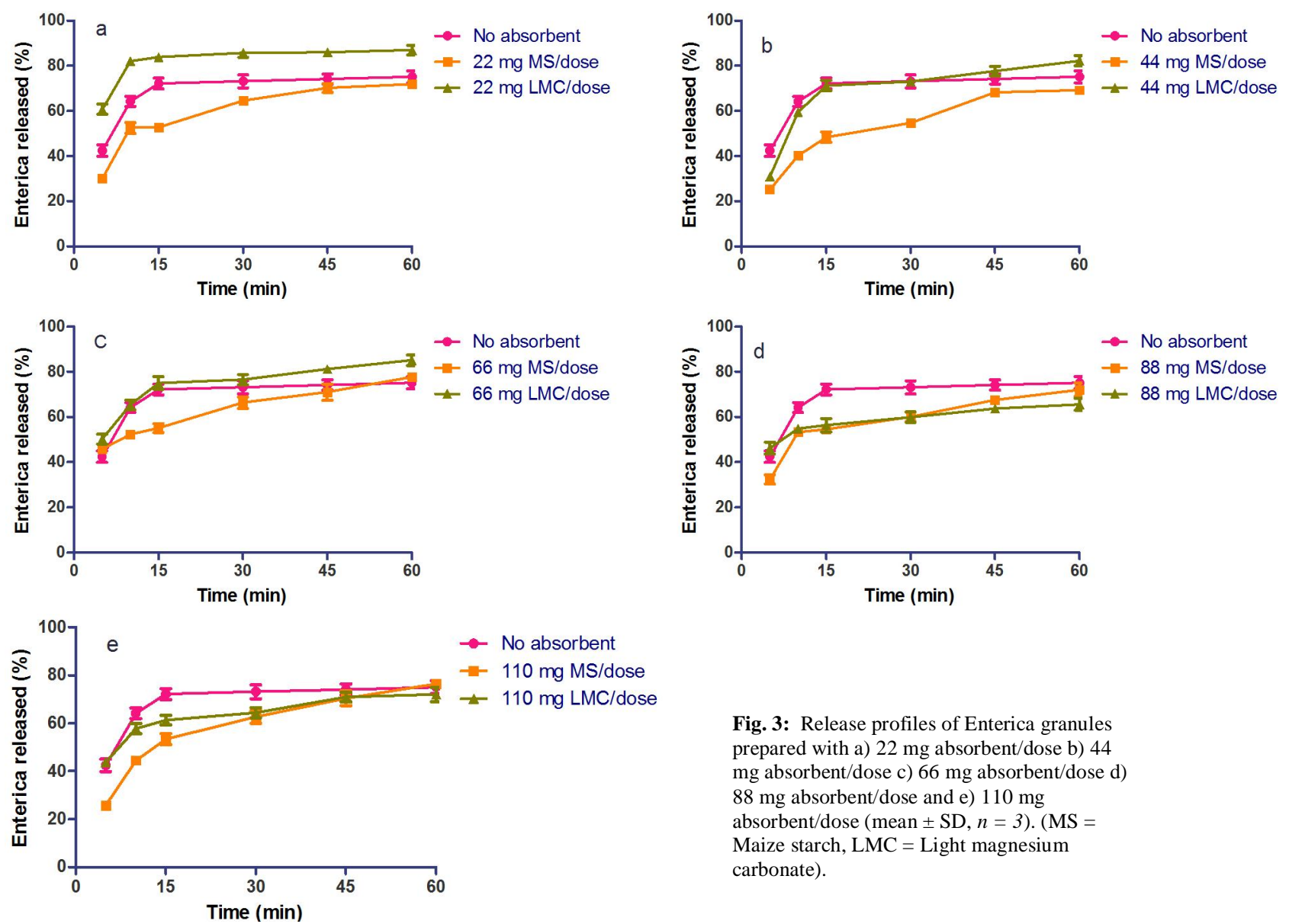

Fig. 3: Release profiles of Enterica granules prepared with a) $22 \mathrm{mg}$ absorbent/dose b) 44 $\mathrm{mg}$ absorbent/dose c) $66 \mathrm{mg}$ absorbent/dose d) $88 \mathrm{mg}$ absorbent/dose and e) $110 \mathrm{mg}$ absorbent/dose (mean $\pm \mathrm{SD}, n=3)$. $(\mathrm{MS}=$ Maize starch, $\mathrm{LMC}=$ Light magnesium carbonate).

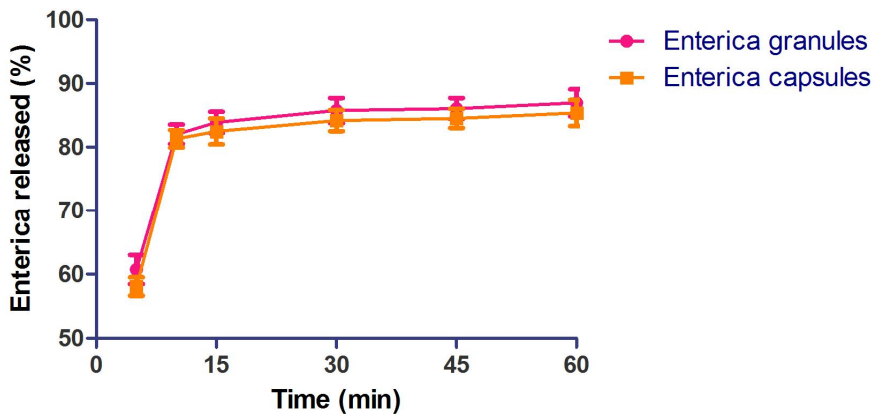

Fig. 4: Release profiles of Enterica granules and oral capsules formulated using $22 \mathrm{mg}$ light magnesium carbonate/ dose of Enterica (mean $\pm S D, n=3$ ).

\section{CONCLUSION}

Enterica oral herbal capsules were successfully developed from Enterica decoction with the use of absorbents. The capsules passed the uniformity of weight, disintegration and in vitro dissolution tests. Enterica oral herbal capsules may therefore be used in place of/or augment the decoction for the treatment of typhoid fever.

\section{ACKNOWLEDGEMENT}

The authors wish to thank the management and technical staff of CSRPM, Mampong-Akwapim, Ghana, for their technical support and their generous provision of plant materials for the study.

\section{REFERENCES}

Aulton ME. 2002. Pharmaceutics: The science of dosage form design, $2^{\text {nd }}$ Ed., Edinburgh: Churchill Livingstone, pp. 205210, 365-395.

Barrett ML. 2004. The handbook of clinically tested herbal remedies, Vol.1, New York: Haworth Press, pp 30-46.

Bayor MT, Johnson R, Gbedema SY. The oral capsule the most appropriate dosage form for Croton membranaceus. International Journal of Pharmaceutical Sciences and Research, 2011; 2(1): 55-62. 
Biswas B, Rogers K, McLaughlin F, Daniels D, Yadav A. Antimicrobial activities of leaf extracts of guava (Psidium guajava L.) on two gram-negative and gram-positive bacteria. Int J Microbiol, 2013; Article ID 746165, 7 pages.

British Pharmacopoeia. 2009. British Pharmacopoeia Commission Stationery Office: Volume III: Appendix XII A1, XII B1, XII C1.

Capasso F, Gaginella TS, Grandolini G, Izzo AA. 2004. Phytotherapy: A quick reference to herbal medicines: Berlin: Springer Verlag, pp. 11-2.

Centre for Scientific Research into Plant Medicine (CSRPM), Biennial Report, 2003-2004, pp77.

Chowdhury AA, Islam MS. Antibacterial activity of Trema orientalis. Dhaka Univ J Pharm Sci, 2004; 3 (1-2):1157.

Database of National Products Association. 2006-2011. Herbal product design and development. (Available at: http://www.wellness.com/reference/therapies/herbal-productdesign-and-development/. [Accessed 23 March 2014].

Fakoya A, Owojuyigbe OS, Fakoya S, Adeoye SO. Possible antimicrobial activity of Morinda lucida stem bark, leaf and root extracts. African Journal of Biotechnology, 2014; 13(3): 471-75.

Gomez-Flores R, Arzate-Quintana C, Quuintanilla-Licea R, Tamez-Guerra R, Monreal-Cuevas E, Rodriguez-Padilla C. Antimicrobial activity of Persea americana Mill (Lauraceae) (Avocado) and Gymnosperma glutinosum (Spreng.) Less (Asteraceae) leaf extracts and active fractions against Mycobacterium tuberculosis. American-Eurasian Journal of Scientific Research, 2008; 3 (2): 188-194.

Jagessar RC, Mohamed A, Gomes G. An evaluation of the antibacterial and antifungal activity of leaf extracts of Momordica charantia against Candida albicans, Staphylococcus aureus and Escherichia coli. Nature and Science, 2008; 6(1), 1-14.

Johnson R, Adotey J, Bayor MT, Annan K. Release profile of extracts of Bridelia ferruginea leaf and Canthium glabriflorum stem bark from different absorbents. International Journal of Pharmaceutical Sciences and Research, 2010; 1(8 Suppl.): 111-117.

Johnson R, Bayor MT, Adotey J. Formulation and evaluation of Bridelia ferruginea and Canthium glabriflorum herbal capsules. International Journal of Contemporary Research and Review, 2011; 2(1): 6-10.
Kumadoh D, Adotey J, Ofori-Kwakye K, Kipo SL, Prah T, Patterson S. Formulation of oral capsules from Asena herbal decoction used traditionally in Ghana for the treatment of arthritis. World Journal of Pharmacy and Pharmaceutical Sciences, 2014; 3 (7): 1824-33

Kumadoh D. 2011. Formulation and evaluation of capsules from Asena and Enterica preparations supplied by Centre of Scientific Research into Plant Medicine (CSRPM), Mampong, Ghana. MPhil thesis, Kwame Nkrumah University of Science and Technology, Kumasi, Ghana, pp. 97.

Kunii D, Levenspiel O.1991. Fludization engineering: solid dosage forms, powders and granules; 2nd ed., New York: John Wiley \& Sons, pp. 23-34.

McCarty AJ. Direct powder blends for encapsulation and tablet compression. Amer Pharm Rev, 2004; 7(1): 94-100.

McGaw LJ, Jäger AK, van Staden J. Antibacterial, anthelmintic and anti-amoebic activity in South African medicinal plants. J Ethnopharmacol, 2000; 72 (1-2): 247-63.

Olayemi FO, Raji Y, Adegoke OA, Oyeyemi MO. Haematological and some biochemical profiles in male rats treated with Cnestis ferruginea (de Candolle) root extract and its pure fractions. African Journal of Pharmacy and Pharmacology, 2013; 7(20): 1231-1235.

Podczeck F, Jones BE. 2004. Pharmaceutical capsules, $2^{\text {nd }}$ Ed., Pharmaceutical Press, UK, pp. 101.

Shittu OB, Olabode OO, Omemu AM, Oluwalana SA, Adeniran S, Akpan I. Phytochemical and antimicrobial screening of Spondias mombin, Senna occidentalis and Musa sapientum against Vibrio cholera. International Journal of Current Microbiology and Applied Sciences, 2014; 3 (5): 948-961.

Staniforth J, Aulton ME. 2007. Powder flow. In: Aulton ME. (ed.), Pharmaceutics - the design and manufacture of medicines. $3^{\text {rd }}$ Ed., London, Churchill Livingstone, p. 168-179.

\section{How to cite this article:}

Kumadoh D., Adotey J., Ofori-Kwakye K., Kipo S. L., Prah T., Patterson S. Development of oral capsules from Enterica herbal decoction-a traditional remedy for typhoid fever in Ghana. J App Pharm Sci, 2015; 5 (04): 083-088. 